\title{
Subway Risks Assessment in Different Construction Stages using AHP and TOPSIS
}

\author{
Arsalan Khosravizade ${ }^{1 *}$ and Mohammad Sharifipour ${ }^{2}$ \\ ${ }^{1}$ Civil Department, Engineering Faculty, Islamic Azad University, Khorasgan Branch, Isfahan, Iran; \\ Arsalan.aka@gmail.com \\ ${ }^{2}$ Civil Department, Engineering Faculty, Razi University, Kermanshah, Iran; \\ sharifipour@razi.ac.ir
}

\begin{abstract}
Background/Objectives: Considering the population growth the need for more services, demand for more underground space has increased. Underground structures including tunnels have been developed mostly because of the increased safety and decrease in space limitations at ground level. Methods/Statistical Analysis: This research has reached some results about prioritizing the risks according to the categorization of designing, execution, finance, HSE and cultural problems through determining the risks according to the indices of contingency and their impact using hierarchical AHP decisionmaking and TOPSIS algorithms along with collecting field data in the form of a questionnaire from experts and analyzing them leading to some suggestions for resolving them. Findings: In this research we find that the most critical risks of tunneling projects, are respectively landfall with risk score of 0.984 , unsystematic excavation with risk score of 0.975 , tolls with a risk score of 0.962 , explosion with a risk score of $0 / 934$, destruction or obstruction of tunnel and access routes with a risk score of 0.878 , influence of toxic and hazardous gases with a risk score of 0.877 , lack of HSE review during the implementation with a risk score of 0.861 and disregarding administrative details caused by high speed implementation with a risk score of 0.819 , which should be considered by authorities in order to reduce and control the risks. Applications/ Improvements: The present research focused on assessment of existing risks in metro projects and prioritizing them by gathering regional information through questionnaires form experts and analysis using multi-criteria decision-making methods consistent with the nature of risk of the project.
\end{abstract}

Keywords: AHP, Hierarchical Decision-Making, Risk, TOPSIS

\section{Introduction}

The increasing growth of the population and the city traffics in metropolises is an undeniable fact and by the growth of the population, extension of the city and increase in the moving vehicles there is a great need for a suitable and fast public transportation system in the city therefore in order to improve the city traffics and prevent the citizens' wasting time and also prevent the pollution of the environment the importance of developing the public transportation system is unavoidable considering the political, economic, commercial and industrial situations in the metropolises. But there have been many risks in constructing a tunnel considering the unknown geological conditions. By prediction and identification of the risks before beginning of a project we can prevent the risks and time delays and the unpredicted increase in the costs by preventive measures.

Identifying the factors and risks, estimating the effect and how to confront them is one of the main standards aspects of managing the risks of the project. The projects of constructing tunnel have a specific importance considering their importance in operational aspects and also the huge investments made in them and also for their complicated nature and the majority of uncertainties about them including how to encounter the unpredicted geological conditions and the natural disasters like flood and earthquake. Identifying the risks and prioritizing and their mutual influence on each other in the tunnel for the purpose of taking measures and being prepared

\footnotetext{
*Author for correspondence
} 
to encounter them and taking the necessary measures to reduce or eliminate the possible risks is an issue which could help manage the risks.

The first step in the risk management process is identifying the risk in which the potential risks about the projects of constructing a tunnel have been identified as an integral part of identifying the risk. The categorization of the risk helps to organize different risks which influence the project.

\section{Research Literature}

In this section, first assessing and prioritizing the risks in the tunnel have been discussed and then different methods of assessing the risk and reviewing the definition of each one are studied.

In order to assess and prioritize the risks in the tunnel construction problems first different general categorization of the tunnel is mentioned. Tunnels are categorized in three groups according to their application features, depth, type of the land and the drilling method: transportation tunnels, industrial tunnels and mineral tunnels.

By different researches and articles which were studied, some started ranking and studying the risks by emphasizing on their matrix of contingency and impact and many have just made qualitative and semiquantitative assessments. It is worth mentioning that many of these individuals have concentrated on one single affecting factor in the risk occurrence in their researches and have tried to assess the risk by studying this factor and measure its influence. Jannadi ${ }^{1}$ defined the different types of potential factors in the open drilling projects in Arabia, studied the risks and assessing them in these projects. Studying the process of managing the risks in underground projects and construction of a tunnel, Reilly and Parker ${ }^{2}$ determined the cost and time needed for designing and construction in a probability function from the point of risk and estimated the correlation and independence coefficient of different risks considering two common indices of probability and impact of the risk in order to assess the risk. The International Tunneling Insurance Group ${ }^{3}$ studied the common method of probability and the impact of the risk and the response to the risk by emphasis on the insurance by the help of major insurance companies and some of the assemblies associated with the projects of the tunnel construction. Some have presented the probability models and statistical analysis in order to assess the risks such as the tunnel's safety, estimating the cost and time needed for the projects of tunnel construction using the Monte Carlo simulation technique or other techniques. Kwangho, et al. ${ }^{4}$ presented a strategy for determining a suitable and optimized maintenance system as well as the advance rate on the basis of risk analysis and reached a probability distribution using the Monte Carlo simulation technique according to many uncertainties about the parameters and features of the surrounding grounds. Isaksson and Stille ${ }^{5}$ studied different risk factors of the tunneling machines and their effects on time and costs required for drilling a tunnel, and presented a probability model in order to estimate the cost and time required for the projects of tunnel construction. OECD (Organization for Economic Cooperation and Development) ${ }^{6}$ studied the rate of accidents, fire and traffic in railway and road tunnels during several years and analyzed them statistically in order to appropriately assess, analyze and predict the risks at the time of the accident. Some of these individuals have estimated the displacement of the ground and the rate of the damage to structures and adjacent tunnels by presenting complicated models and computer programs. Some of these articles are introduced in the following. Studied land subsidence caused by digging a tunnel and the damage to adjacent installments ${ }^{7,8}$. Studied the response to risks in order to control and manage them in tunnel digging operations in the center of the city under complicated conditions of the land ${ }^{9}$. Okazaki, et al. $^{10}$ studied the convergence rate and settlement displacement in a tunnel construction operation in Japan using the data collected from the core drills and also the measured magnetic field strength (using the aerial survey with helicopter) considering the connection between all of the collected data. Used a questionnaire and statistical analysis of the expert opinions and suggested a fivepoint Likert-type scale ranging from 1 to 5 to complete the questionnaire in order to analyze the fire risk in road tunnels ${ }^{11}$. Identified some geological risks including landslide, roof collapse, and water leak and presented Natural Risk Index (NRI) and Safety Factor (SF) and zoned the studied land accordingly ${ }^{12}$.

In the following, different methods for risk assessment are discussed. During the past decade, many researchers have suggested different techniques for analyzing risks in the construction industry. Among different techniques, the fuzzy technique has been used vastly in research studies on construction management. The fuzzy research 
studies on construction management are divided in two main groups:

- Fuzzy set/Fuzzy logic

- A combination of the fuzzy technique with the practical programs such as decision-making, modeling, operation and assessment. For example, in ${ }^{13,14}$ a strategy presented for assessing the fuzzy risk for the occupational hazards in the construction industry. In this study, a semi-quantitative approach was made in which the fuzzy set theory was being used. In this study three approaches of QFD, fuzzy ANP, and fuzzy FMEA were used. In this research important types and factors of risks in construction were determined and the preventive and improvement measures were presented. Presented a model for risk management in the construction industry using the combination of FAHP and FFMEA. In this method, contingency, impact and identification probability or control were defined in five terms as "too many, many, average, little, very little" and then every lingual term was turned into trapezoidal fuzzy numbers. Eventually using a critical analysis software program Risk Priority Number (RPN) was calculated ${ }^{15}$. They used the FMEA method to integrate risk management for OHS, quality and environment improvement in projects of the construction industry. In this study, FMEA was concentrating on OHS risks, environment and quality management in construction which was carried out according to three aspects of contingency, impact and identification probability for OHS risks, quality and environment. In this study, 20 potential risks were identified and studied including falling from the roof, falling from the casement frames on floors, collapse incidents in construction, elevator incidents, fire and explosion. In the end, the results of this study showed that five potential risks have been identified as unacceptable risks including falling from casement frames on the floor, falling of objects and collision with operational equipment, falling from the elevator opening and falling from the scaffolding ${ }^{16}$. Suggested a method for assessing the risks workers are exposed to in construction projects and used the fuzzy rule-based code for the safety analysis. In this study, historical data of the incidents, subjective judgment of the experts and the safety level of a workshop were used and also three parameters of incident probability, safety level and the intensity of the incident were used as the input parameters for the fuzzy logic ${ }^{17}$. Suggested risk according to fuzzy reasoning and AHP. In this study, risk prioritizing is performed according to three main parameters of Risk Limit (RL), Risk Severity (RS) and Factor Index (FI). These parameters were first defined in lingual terms and then turned into trapezoidal fuzzy numbers and hierarchical analysis was used in risk factor structure. Eventually the IF-THEN rule was used to calculate the output of Risk Magnitude (RM) ${ }^{18}$.

\section{Theoretical Foundation of the Research}

The activities of the construction industry are always involved with risk because of the natural complexities and the parties involved.

Risk can be defined as "an accident or an event which can has negative effects on the components of the project including goal, quality, implement, plan and cost". Therefore, a systematic strategy is needed to encounter the risks ${ }^{19}$. There are two perspectives in the definition of the risk. One perspective considers the risk as only a loss and the second one considers it both a loss and a profit. The result of these perspectives is different definitions for risk management. In the present research the negative aspect is considered.

Project management, knowledge application, skill, tools and the techniques related to the project activities are to provide the necessities of the project. Project management has nine project management knowledge areas. These nine main areas must be implemented at the stage of project management execution and must be balanced with other parts in order to improve the project according the defined goals. The mentioned areas are as follows ${ }^{20}$ : integrated management; communication management; project time management; project quality management; site management; project cost management; human resources management; project risk management; and goods and materials management.

\subsection{Risk Management}

In the past decades risk management process has turned into a series of regular and official processes because of the fast technological developments. Therefore, risk management has become a professional issue ${ }^{21}$.

A systematic risk management has the following benefits: 
- Assessing and ranking the identified risks.

- Concentrating on the main risks.

- Providing diverse informed decisions.

- Minimizing the potential of a harmful event.

- Controlling the aspect of uncertainty.

- Industrializing the company's role and the individual's responsibility in risk management.

- Identifying methods in order to improve the project.

\subsection{Stages of Risk Management and Assessment}

Risk management refers to the process of identification, assessment and control of the potential risks. Every part has used the term risk management with its own conditions and matches its meaning with the conditions of its own complex. Risk management frequently follows a continuous and systematic process of identifying, measuring, analyzing, controlling, preventing, reducing and assessing the risk and gaining credit. The components of a risk management system include risk identification, risk assessment, response to risk, risk control and monitoring ${ }^{22}$.

After mentioning the risk management stages, another important issue is the time and the way it is managed. Different researchers have a same opinion in this regard. It is believed that risk management must begin from the primary stages of the project, since in the designing stage which is a primary stage; the main risks could be reduced or avoided completely. Also, risk management stages regardless of the groups in which they are categorized, must be implemented cyclically ${ }^{23}$.

\subsection{Decision-Making by the use of AHP}

The Analytic Hierarchy Process (AHP) is a strong method of decision-making. This method is used when decisionmaking process is encountering different decision factors. The mentioned factors could be qualitative or quantitative. Also decision-making could be executed individually or by a group. Due to the ease and at the same time practicality of AHP implementation in organizations and decision-making centers more than other methods of action research it is used more often. AHP is a decisionmaking method through which the decisions can be made depending on different criteria or multi-criteria. It can be precisely stated that by AHP the decision-making problem is structured and then different existing options are compared according to the mentioned criteria and the priority of each one is specified. This technique was built on the basis of paired comparison and gives managers the opportunity to study different scenarios. Since AHP is naturally simple and yet comprehensive, it has been welcomed by different managers and users and also has been under consideration by the scientific parties in the past twenty years ${ }^{24,25}$.

AHP is one the most comprehensive designed systems for decision-making with multi-criteria because this technique provides the possibility to formulating the problem hierarchically and also makes it possible to consider different quantitative and qualitative criteria in the problem. This process considers different options in decision-making and makes it possible to analyze above and under the criteria. Moreover it is built on the basis of paired comparison which simplifies judgment and calculations and also shows the compatibility and incompatibility level of the decision which is among the excellent benefits of this technique in multi-criteria decision-making. Moreover it has a strong theoretical principle which is built according to obvious principles ${ }^{25}$.

Hierarchy structuring refers to a kind of dendriform structure with different levels, so that firstly the goal is and then the related criteria (each criterion could have some sub-criterion) are defined. In the last level stand the options which are going to be prioritized or one is going to be chosen from them. Types of hierarchy structuring include structural hierarchy and task hierarchy.

In AHP the elements of each level are compared in pairs with the higher level element; and their weight called the relative weight is calculated. Then by combining relative weights, the final weight of every option called the absolute weight is determined. All of the comparisons in AHP are made in pairs. In these comparisons, decision makers will use verbal judgments so that if element $i$ is compared to the element $j$, the decision maker would say that element $i$ precedes element $\mathrm{j}$ in one of the following states ${ }^{25}$ :

- $\quad$ Extremely preferred

- Very Strongly Preferred

- Strongly Preferred

- Moderately Preferred

- Equally Preferred

Table 1. Values of preferences for paired comparisons ${ }^{21}$

\begin{tabular}{lc}
\hline Preferences (Verbal Judgments) & Numerical value \\
\hline Extremely Preferred & 9 \\
Very Strongly Preferred & 7 \\
Strongly Preferred & 5 \\
Moderately Preferred & 3 \\
Equally Preferred & 1 \\
Preference between the above intervals & $2,4,6,8$ \\
\hline
\end{tabular}


These judgments are changed by Saati into quantitative values from 1 to 9 which are specified in Table 1.

\subsection{TOPSIS}

TOPSIS algorithm is performed in 6 steps as follows:

Step 1: converting the existing decision matrix to an immeasurable matrix using the following formula: $\mathrm{n}_{\mathrm{ij}}=\frac{\mathrm{r}_{\mathrm{ij}}}{\sqrt{\sum_{\mathrm{i}=1}^{\mathrm{m}} \mathrm{r}_{\mathrm{ij}}^{2}}}$

Step 2: Creating weighted immeasurable matrix (V) as an input of algorithm $\mathrm{W}$ with a given vector.

$W=\left(w_{1}, w_{2}, \ldots, w_{n}\right.$

$\mathrm{V}=\mathrm{N}_{\mathrm{D}} \cdot \mathrm{w}_{\mathrm{nxn}}=\left[\begin{array}{ccc}\mathrm{V}_{11} & \cdots & \mathrm{V}_{1 \mathrm{n}} \\ \vdots & \vdots & \vdots \\ \mathrm{V}_{\mathrm{m} 1} & \cdots & \mathrm{V}_{\mathrm{mn}}\end{array}\right]$

Where $N_{D}$ is the matrix in which scores of indexes have become immeasurable and comparable and $w_{n \times n}$ is the diagonal matrix in which only the elements of its original diameter can be non-zero.

Step 3: Determining the ideal solution and negative ideal solution so that, for an ideal option $\mathrm{A}^{+}$and negative ideal $\mathrm{A}^{-}$is defined as:

$A^{+}=\left\{\left(\max _{i} V_{i j} \mid j \in J\right),\left(\min _{i} V_{i j} \mid j \in J^{\prime}\right) \mid i=1,2,3, \ldots, m\right\}=\left\{V_{1}^{+}, V_{2}^{+}, \ldots, V_{j}^{+}, \ldots, V_{n}^{+}\right\}$

$A^{-}=\left\{\left(\min _{i} V_{i j} \mid j \in J\right),\left(\max _{i} V_{i j} \mid j \in J^{\prime}\right) \mid i=1,2,3, \ldots, m\right\}=\left\{V_{1}^{-}, V_{2}^{-}, \ldots, V_{j}^{-}, \ldots, V_{n}^{-}\right\}$

$J=\{j=1,2, \ldots, n \mid j \in$ Benefit $\}$

$\mathrm{J}^{\prime}=\{\mathrm{j}=1,2, \ldots, \mathrm{n} \mid \mathrm{j} \in$ Cost $\}$

Step 4: Calculating the size of separation (distance). The distance of the $\mathrm{i}^{\text {th }}$ option to the ideals using Euclidean method is as follows:

$\mathrm{d}_{\mathrm{i}+}=$ distance $\mathrm{i}$ option of positive ideal $=\sqrt{\left\{\sum_{\mathrm{j}=1}^{\mathrm{n}}\left(\mathrm{V}_{\mathrm{ij}}-\mathrm{V}_{\mathrm{j}}^{+}\right)^{2}\right\}} ; \mathrm{i}=1,2, \ldots$,

Step 5: Calculating the relative proximity of $A_{i}$ to the ideal solution. This relative proximity is defined as follows:

$\mathrm{cl}_{\mathrm{i}+}=\frac{\mathrm{d}_{\mathrm{i}-}}{\mathrm{d}_{\mathrm{i}+}+\mathrm{d}_{\mathrm{i}-}} ; 0 \leq \mathrm{cl}_{\mathrm{i}+}$

It is seen that if $A_{i}=A^{+}$then $d_{j+}=0$ and $c_{l i+}=1$; and if $A_{i}=A^{-}$then $d_{j-}=0$ and $c_{l i+}=0$. Thus, the closer $A_{i}$ to the ideal solution $\left(A^{+}\right)$, the closer the value $c l_{i+}$ to the unit.
Step 6: Ranking options. Based on the descending order of $c_{i+}$ the existing options of the given problem can be ranked ${ }^{26}$.

\section{Results}

Three questionnaires were provided for assessing tunnel risks in various stages of construction, and were distributed among the factors involved in tunnel projects including consulting engineers, contractors and the employer. Each of the questionnaires was distributed among 35 members and 25 cases were collected. In order for a better understanding of the questions, each of these questions was explained for the respondents. Rating the criteria was performed based on the main cases of each of the issues of contingency and intensity, based on the principles of risk management with regard to the issues and problems in subway construction workshops and comparisons between risk factors for each criterion according to the rating.

In order to rate the criteria in terms of contingency, three factors were evaluated: inadequate management controls, poor performance of HSE, personal factors such as low accuracy, inexperience and irresponsibility. Finally, the total mean scores of the criteria were considered. Ultimately, these mean values entered into AHP analysis and were investigated in Expert Choice software program. The following Figures show the results of this investigation.

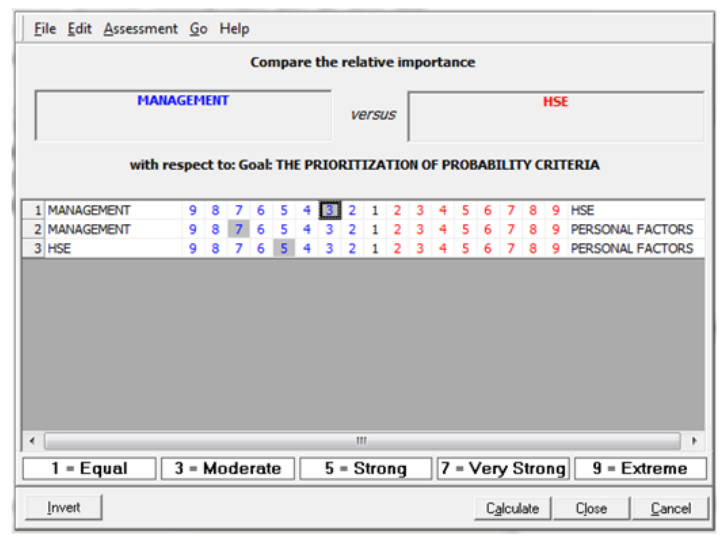

Figure 1. Rating of the contingency criteria. 


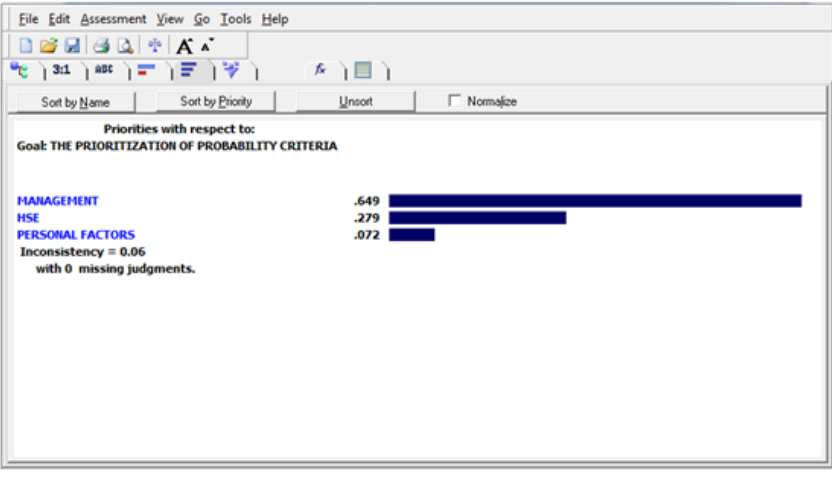

Figure 2. Relative weight of the contingency criteria (EC output).

As shown in Figures 1 and 2, management control was the most important measure with a score of 0.649 and respecting HSE cases and personal factors, respectively, with .279 and .072 were in the next rankings.

In order to rate the criteria in terms of intensity four factors of financial outcomes, physical outcomes, time outcomes and effect on project implementation quality were studied. Finally the overall mean scores of the criteria were considered. In the end, these mean values entered into AHP analysis and were investigated in Expert Choice software program. The following figures show the results of this investigation.

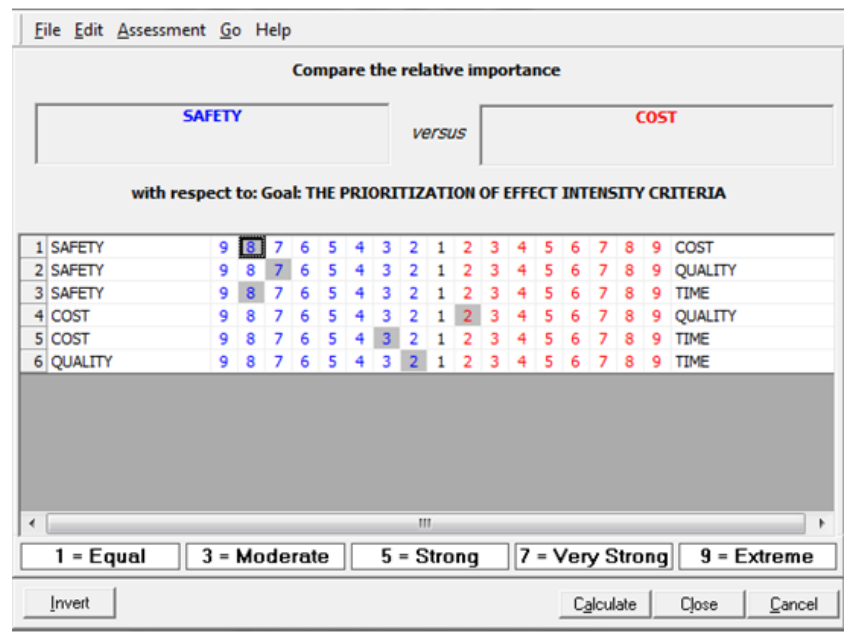

Figure 3. Rating of the intensity criteria.

As it was seen in Figures 3 and 4, the safety factor with a score of 0.703 was the most important criteria. Project implementation quality, financial issues and project completion time, respectively, with .143 and .104 and .059 were in the next rankings.

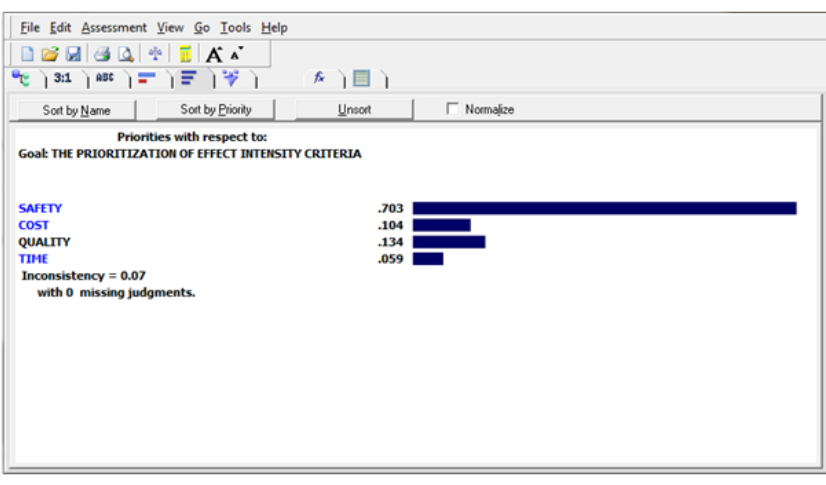

Figure 4. Relative weight of the intensity criteria (EC output).

\section{Case Study}

Regarding to the objectives of this study, risks identification is one of the most important steps in the risk management process, because without complete identification of project risks, dealing with risk assessment is not possible; the obtained results are useless and the systematic and planned response to the risks of tunneling projects that is the primary purpose of tunnel risk management, is not possible irrespective of this issue. In this section, the risks of tunneling projects were identified based on library studies, reviewing articles and related theses and interviews with experts. Accurate identification of risks in tunneling projects in Isfahan can be a great help to offering measures and strategies for reducing or completely eliminating the risks. Due to lack of data and documentary information of the situation of tunneling risks, it seemed that the best way to get such information is to use a questionnaire. Therefore, questionnaires were designed based on the identified risks. In the prepared questionnaires, to evaluate the intensity, the effect of each risk on financial, physical, time and qualitative criteria was taken into account. Risks related to designing issues include 7 risk factors. The results of calculations and analysis of this risk, is provided in Figure 5.

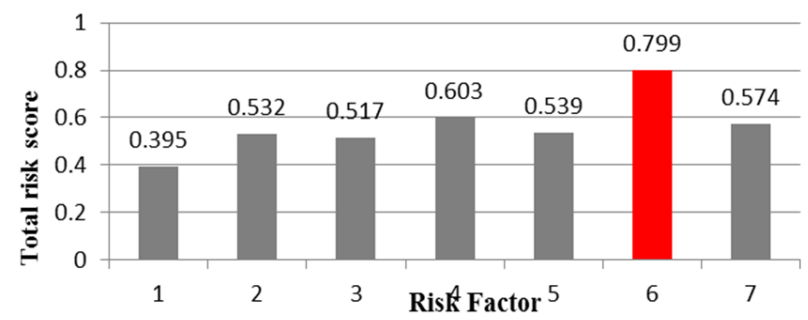

Figure 5. Score obtained from the risks related to designing issues. 
As the graph above shows, in this set of risk factors, factor 6 (insufficient geotechnical studies due to poor management) accounted for the highest score. This risk factor will be considered as an index reflecting the total importance of the factors in this section. Then, the risk factor entitles as traffic routes due to lack of alternative routes management with a score of 0.603 received the second position.

Risks related to administrative issues include 18 risk factors. The results of the calculations and analysis for the above risk are also provided in Figure 6.

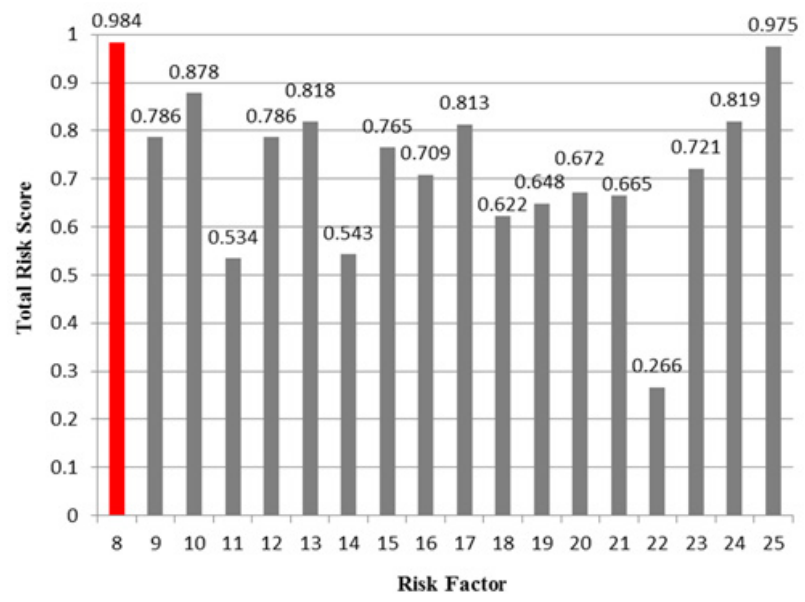

Figure 6. Score obtained from the risks related to administrative issues.

In this set of risk factors, factor 8 , landfall, with a risk score of 0.984 had the highest score. This risk factor also was considered as an index indicating the total importance of the factors in this section. Then, unsystematic excavation with a risk score 0.975 has received the highest risk value indicating the intensity of poor attention to issues relating to the excavation.

Risks related to financial issue include 2 risk factors. The results of calculations and analysis for the above risk are shown in Figure 7.

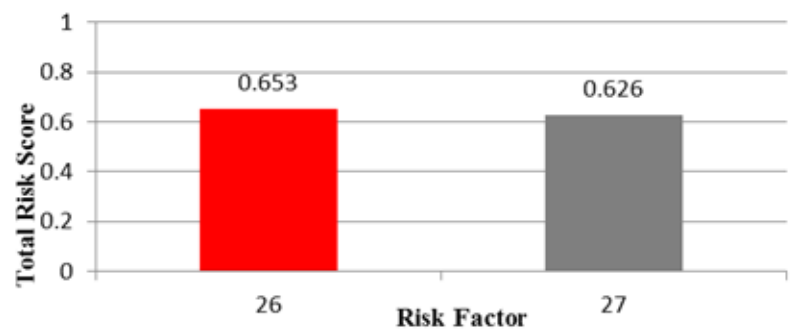

Figure 7. Score obtained from the risks related to financial issues.
In this set of risk factors, risk factor 26 with a score 0.653 had the highest score. This risk factor also was considered as an index indicating the total importance of the factors in this section.

Risks related to HSE issues include 6 risk factors. The results of the calculations and analysis for the above risk are shown in Figure 8.

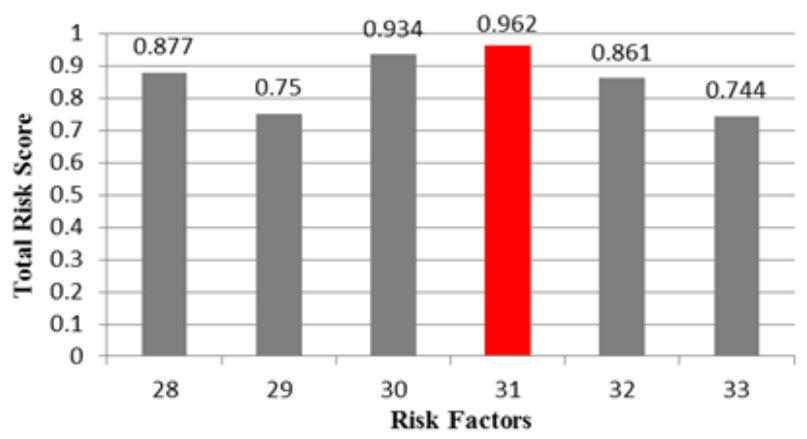

Figure 8. Score obtained from the risks related to HSE issues.

In this set of risk factors, risk factor 31 with a score of 0.962 had the highest score. This risk factor was also considered as an index indicating the total importance of factors in this section. Then, the risk factors of explosion received the second position with a score of 0.934 .

Risks related to cultural issues include 2 risk factors. The results of the calculations and analysis for above risk are provided in Figure 9.

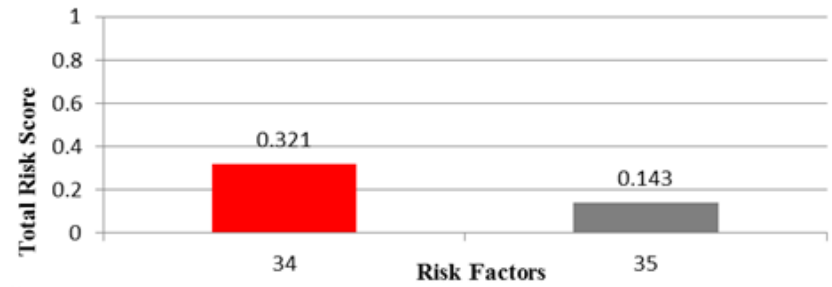

Figure 9. Score obtained from the risks related to cultural issues.

In this set of risk factors, risk factor 34 with a score of 0.321 had the highest score. This risk factor was also considered as an index indicating the total importance of the factors in this section.

In general, it is observed that the most important risks are related to tunneling projects, landfall, unsystematic excavation, tolls, explosions, destruction or obstruction of tunnels and access routes, and influence of toxic and hazardous gases, lack of HSE review during the implementation and disregarding administrative details 
resulting from high speed implementation that must be taken into account by authorities in order to reduce and control the risks.

\section{Discussion and Conclusions}

According to the study, the most important risks of tunneling projects, are respectively landfall with risk score of 0.984 , unsystematic excavation with risk score of 0.975 , tolls with a risk score of 0.962 , explosion with a risk score of 0/934, destruction or obstruction of tunnel and access routes with a risk score of 0.878 , influence of toxic and hazardous gases with a risk score of 0.877 , lack of HSE review during the implementation with a risk score of 0.861 and disregarding administrative details caused by high speed implementation with a risk score of 0.819 , which should be considered by authorities in order to reduce and control the risks.

The present research focused on assessment of existing risks in metro projects and prioritizing them by gathering regional information through questionnaires form experts and analysis using multi-criteria decisionmaking methods consistent with the nature of risk of the project. However, drawing conclusions for dealing with risks in project needs more studies; with regard to the response of evaluated risks consideration to the following matters are recommended:

- Selecting appropriate administrators who in addition to having adequate administrative skills, are familiar with knowledge management and project control and have required administrative experience, because an efficient administrator has the ability to control risks before being intensified and converted to crises.

- Matching available physical condition of the region to facilities and machinery used prior to the start-up.

- Extracting maximum information with the appropriate budget allocation and enough time for conducting studies especially geotechnical and infrastructural studies, as well as having adequate database of relevant references.

- If possible, the route of the tunnel should be selected with an appropriate distance from infrastructural equipment so that in potential landfall the least harm and damage is imposed.

- Using experts and selecting a contractor with a good record.

- Attention to safety issues and giving priority to the work environment HSE.
- Proper implementation of drilling and correct concreting tunnel wall.

- Preparation of accurate and detailed administrative plans, tunnel route mapping and monitoring more closely on the execution plan.

\subsection{Recommendations for Future Research}

- Assessment of tunnel risks using other multi-criteria decision- making methods.

- Using the presented model for evaluating the risk of other constructive projects.

- Comparing this method with other risk assessment methods in tunneling projects.

\section{References}

1. Jannadi OA. Risks associated with trenching works in Saudi Arabia. Building and Environment. 2008 May; 43(5):77681.

2. Reilly J, Parker H. Benefits and life-cycle costs of underground projects. Proceedings, AITES-ITA World Tunnel Congress; Prague. 2007. p. 679-84.

3. Bravery P, Cross S, Gallagher R, Hautefeuille O, Reiner H, Spencer M, Smith P, Stolfa A, Wannick H. A Code of Practice for Risk Management of Tunnel Works. Munich: The International Tunnelling Insurance Group; 2006.

4. Ng MF, Tummala VR, Yam RC. A risk-based maintenance management model for toll road/tunnel operations. Construction Management and Economics. 2003 Jul; 21(5):495510.

5. You K, Park Y, Lee JS. Risk analysis for determination of a tunnel support pattern. Tunneling and Underground Space Technology. 2005; 20(5):479-86.

6. Isaksson T, Stille H. Model for estimation of time and cost for tunnel projects based on risk evaluation. Rock Mechanics and Rock Engineering. 2005 Nov; 38(5):373-98.

7. Jovanovic A, Renn O, Schroter R. Social Unrest, OECD Reviews of Risk Management Policies. OECD Publishing; 2012.

8. Son M, Cording EJ. Tunneling, building response and damage estimation. Tunnelling and Underground Space Technology. 2006 Jul; 21(3):326.

9. Herrenknecht EM, Bappler K. Mastering risks during mechanized excavation in urban centers with highly complex ground conditions. Tunnelling and Underground Space Technology. 2006 May; 21(3):260-73.

10. Gandit M, Kouabenan DR, Caroly S. Road-tunnel fires: Risk perception and management strategies among users. Safety Science. 2009 Jan; 47(1):105-14.

11. Sanchez MA, Foyo A, Tomillo C, Iriarte E. Geological risk assessment of the area surrounding Altamira Cave: A proposed natural risk index and safety factor for protection of prehistoric caves. Engineering Geology. 2007 Nov; 94(3):180-200. 
12. Liu HT, Tsai YL. A fuzzy risk assessment approach for occupational hazards in the construction industry. Safety Science. 2012 Apr; 50(4):1067-78.

13. Siadati S, Shahhosseini V. Comparison of modern structural systems based on a fuzzy analytical hierarchy process. Indian Journal of Science and Technology. 2015 Jul; 8(13); 1-5.

14. Montazeri-Gh M, Mahmoodi-k M. Development a new power management strategy for power split hybrid electric vehicles. Transportation Research Part D: Transport and Environment. 2015 Jun; 37:79-96.

15. Zeng SX, Tam CM, Tam VW. Integrating safety, environmental and quality risks for project management using a FMEA method. Engineering Economics. 2015 Oct; 66(1):43-56.

16. Gurcanli GE, Mungen U. An occupational safety risk analysis method at construction sites using fuzzy sets. International Journal of Industrial Ergonomics. 2009 Mar; 39(2):371-87.

17. Zeng J, An M, Smith NJ. Application of a fuzzy based decision making methodology to construction project risk assessment. International Journal of Project Management. 2007 Aug; 25(6):589-600.

18. Arikan A E. Development of a risk management decision support system for international construction projects (Doctoral dissertation, Middle East Technical University), 2005.
19. Duncan WR. A Guide to the Project Management Body of Knowledge (PMBOK ${ }^{\circledast}$ Guide). 5th ed. USA: Project Management Institute; 2001.

20. Al-Salman AA. Assessment of risk management perceptions and practices of construction contractors in Saudi Arabia [Doctoral dissertation]. King Fahd University of Petroleum and Minerals; 2004.

21. Cooper DF. Project risk management guidelines: Managing risk in large projects and complex procurements. USA: John Wiley and Sons Ltd; 2004.

22. Rafi-Zadeh I, Ardeshir A. Qualitative analysis of construction projects with a fuzzy approach. The $5^{\text {th }}$ International Conference on Project Management; Tehran, Iran. 2009.

23. Al-Salman AA. Assessment of risk management perceptions and practices of construction contractors in Saudi Arabia [Doctoral dissertation]. King Fahd University of Petroleum and Minerals; 2004.

24. Gholami MHM, Ariani J. Prioritizing productivity enhancement strategies in HSE management using AHP. The $3^{\text {rd }}$ National Conference on HSE; Tehran, Iran. 2010.

25. Ghodsipour SH. The Analytic Hierarchy Process (AHP). 10 ed. Tehran's Amir Kabir University Press (Tehran Polytechnic); 2012.

26. Rezaeefar A, Jabalameli MS, Cheeibakhsh A. Rating project risks using multi-criteria decision-making methods. The $2^{\text {nd }}$ International Conference on Project Management; Tehran, Iran. 2005. 